\title{
An investigation of summer house vacationists environmentally sustainable behaviors
}

\author{
Selin Kama ${ }^{1}$, Önder Yayla ${ }^{2}$
}

\begin{abstract}
There is a problem situation between discourse and practice in many of the existing studies on sustainability. That brings out sustainability is an unrealistic ideal, and it is connected to the conspicuousness and statue. In the literature, the perception and behavior of summer house vacationists on environmental sustainability have not been found in any studies. Therefore, the opinions of the summer house vacationists associated with environmental sustainability and environmentally sustainable behavior were investigated in this study. Moreover, the aim of this research is to uncover the opinions of the summer house vacationists about the sustainability of the environment to determine how the views reflect the behavior. In this context, quantitative research method was applied to sample group consisting of 140 summer house vacationists. In this study, the sample group was selected from different parts of Turkey with purposeful sampling technique. The data was analyzed with independent sample t-test and one-way analysis of variance (ANOVA). The results of the analysis showed that summer house vacationists vary depending on their demographic characteristics in four-dimensions. The data obtained by the research revealed sustainability behavior of consumers which is important for the tourism sector.
\end{abstract}

Keywords: Sustainability, sustainable behavior, sustainable tourism behavior, summer house vacationist

To cite this article: Kama, S., Yayla, Ö. (2017). An investigation of summer house vacationists environmentally sustainable behaviors. Journal of Tourism Theory and Research, 3(1), 16-24. DOI: 10.24288/jttr.279176

\footnotetext{
${ }^{1}$ Res. Asst, Anadolu University, selinkama@anadolu.edu.tr

${ }^{2}$ Res. Asst, Anadolu University, onder.yayla@gmail.com
} 


\section{Introduction}

The environment which is expressed through a combination of social, biological, physical and chemical factors influenced by any kind of action which contains the human element during the development process of human history. This effect has led to the deterioration of the natural cycle in the environment of self-preservation and renewal process over time because of the methods and mechanisms used in the production and consumption. Thus, the increasing rate of exhaustion of environmental resources since the industrial revolution has become the subject of many scientific studies.

Environmental Performance Index (EPI) is an important study to evaluate the environment of countries according to the environmental health and ecosystem vitality. Yale University's EPI has been implemented every two years since 2006 with 22 performance indicators. According to assessments, Turkey experienced a decline in previous years in the environmental performance index with 67.68 points and ranks 99. In the Index; Turkey is located between Eastern Europe and Central Asian countries and falls behind Russia, Ukraine, Macedonia as well as Turkic republics such as Turkmenistan, Azerbaijan and Kazakhstan. This implementation reveals the visible portion of pollution that growing countries created in numbers.

Some studies on sustainability suggest that on the basis of communities, businesses and consumers, sustainability is an unrealistic ideal and related with the conspicuousness and statue. When these statements are compared with the numerical values of environmental degradation, the belief of a problematic situation in between the discourse and the application is increasing. Therefore, the purpose of this study is analyzing the behavior of summer house vacationists in terms of environmental sustainability during their holidays.

\section{Sustainability in the context of consumer}

As a result of an increase participation in tourism activities shaped by sea-sand-sun tourism triangle between 1980-2000 both secondary housing and hotels showed a rapid and unplanned tourism development. As the mass tourism which is dominated by sun, sea and sand lost the economic gain effect in time, a new search has begun (Beyhan and Unugur, 2005). The concept of sustainability in the service sector came to the fore as a result of this search and by creating an important niche market, sustainable tourism has brought new areas into the tourism industry.

WTO (1998) provides the following phrases in the definition of sustainable tourism development:

- Protection of the environment from corruption and transformation, in which it interacts human or not,

- Resume the system of cultural integrity, ecological processes, biological diversity and life-sustaining,

- Satisfy the economic, social and aesthetic needs of people in the destination and manage in a way that can meet the needs of future generations.

In other words, sustainable tourism is a tourism development that meets the needs of the region and presents tourists while preserving opportunities for the future (Leung, Marion and Farrel, 2008).

Sustainability is a phenomenon that can be achieved by acting together as a whole community. This situation raises the need to improve the perception of the environment and sustainability for all individuals in the social sphere. From the point of consumers, sustainability is associated with upgrading the quality of life and life pleasure (Jones, Hill, Comfort and Hillier, 2008). Eventually, people do not buy a vacation where they can be isolated, it is an extension of what daily life is and in a way linked to the other products they buy (Swarbrooke, 1996: 70 cited in Miller, 2010). This considered as an indicator of the desired behavior of tourists differs from the real life selection behavior (Mansfeld, 1995: 73 cited in Miller, 2010). Therefore, in order to understand consumers' attitudes, they need to be separated in the context of sustainability or the environment.

As the literature viewed, it can be seen that there are different groups of people who characterized according to their behavior towards nature. Yucel (2003) states that there are three groups defined by the consumption of natural resources, pollution emission and damaging natural environments. Those groups are separated depending on their average annual income and lifestyle. Trends of environmentalists crystallize 
within these three groups. These groups are poor, middle class and rich. Poor are at the bottom of the pyramid of the world economy. They mostly live in rural areas and provide livelihood from the land and what they collect from forests. The poor cannot afford to splurge. The middle class is seen attentive in the reuse and recycling of materials. In addition, they are the ideal target for all groups who want to balance economies with the environment. The consumer class or rich, who is very prone to the waste and disposable consumption, is considered as a part of their lifestyle (Yücel, 2003). On the other hand, another study classifying consumers according to how environmentalist they are. To show the level of being environmentalist, consumers are handled on separate planes from gray to green. In this classification, it is suggested that one end of this plane is gray or nongreen consumers and on the other hand there are green or green-consumers (Peattie, 2001).

As the tourists bring the preference of the comfort based holidays into the forefront (Yi, Li and Jai, 2016), this may cause a negative orientation for sustainable consumption patterns. However, as the consumption of goods and services in order to create individual differences plays an important role in building the identity of the individual, functionality and exchange value have remained in the background and indicator value has come to the fore. Therefore, because green consumption is a proper attitude to society's norms and values, it provides a framework about the social status of individuals (Elliot, 2013). This type of framework can lead to specific motivation for tourists to exhibit sustainable behavior.

Consumers can support a sustainable environment for many reasons such as materialism, desire for change, curiosity, information needs, psychological benefits, social status and group norms. In fact, many types of research made on the consumers reached the conclusion that they are environmentally conscious and also sensitive to use environmentally friendly products (Karaca, 2013; Choi and Ng, 2011; Lin and Huang, 2011). However, it is also supported by researches that these concerns don't reflect the behavior, although studies support the idea of people make the necessary arrangements for the environment (Budeanu, 2007). Finisterre do Paco and Raposo (2010) emphasize that many of the hotel guests have no idea about green practices of hotels and they have never remained in this type of hotel. Similarly, Khare (2014), states that local community do not know words like recycle, earth-friendly, organic which effect green product purchase behavior in India.

Environmental concerns have environmental consequences and lead to attitudes that are associated with personal experiences, experiences with other individuals and media communication. In general, this attitude is associated with price, product performance, social norms and knowledge (Finisterra do Paco and Raposo, 2010). Values, beliefs and habits which have an impact on sustainability are other social or personal characteristics. While personal norms create a strong positive effect on the willingness to implement a behavior, value and faith have a moderate impact on the behavior (Jansson, Marell and Nordlund, 2010). As well as these factors perceived behavioral control are also referred to as having an impact on the behavior of the Green Hotel (Han, Hsu and Sheu, 2010).

Gilg, Barr and Ford (2005) obtained findings between environmentalists and non-environmentalists, oriented by income, education and age. Accordingly, men who are a low average of age, low-paid and less educated are less environmentalist than women who are the high average of age, higher income and more educated. On the other hand, Bodur and Sarıgöllü (2005) imply that there is a significant relationship between the education level and environmental sensitivity, but age, gender and profession show a nonsignificant relationship. According to Millar and Baloglu (2011) business or leisure travelers want refillable shampoo boxes, energy-saving light bulbs, re-use policies for bed linen and towels, the use of a key card that allows electrical control, availability of recycling bins in the lobby and a green certificate from hotels. However, the authors also argue that tourists are generally sceptical of the eco-label hotels. In another research, Choi and $\mathrm{Ng}$ (2011) express that consumers are attached importance to environmental responsibility of hotels. Therefore, they are against to pay even low prices to the hotel which has low-level environmental initiatives. Yaras, Akan and Sakac1 (2011) indicate that environmental sensitivity has an impact on the purchase decision depending on the average income and the family's budget and price increases have negative effects on the environmentally sensitive purchase behavior. Similarly, Grove, Fisk, Pickett and Kangun (1996) emphasize the necessity of 
determining the prices by considering the tourist's solvency beyond environmental sensitivity. According to the authors, tourists' place in the chain of production and consumption vary depending on the price. Karaca (2013) found a significant relationship between demographic factors and sustainability trends in a similar way in his research to determine the environmental awareness and the trend of using environmentally friendly products. In this context, he determined that there is a significant relationship between the revenue and the purchase behavior.

\section{Method}

\subsection{Data collection}

The population of the study consisted of summer house vacationists residing in various cities in Turkey. The study was conducted by questionnaire, which is a quantitative research method. Questionnaires were applied on summer house vacationists in different parts of Turkey by using purposive sampling method in this study. In this context, the survey was conducted with 141 participants. Due to inadequacy, one of the questionnaires collected has not been included in the analysis.

33 questions prepared by the 5 Likert Rating Scale were asked to sample group to aim at measuring environmental sustainability behaviors and perceptions of sustainability in the study. After the results of the analysis in the first part consisting of 20 questions, eight questions were excluded from the study due to the non-reliability and the invalidity, and analyses were conducted over 12 questions. These 12 questions consist of the part that measures the level of environmental sustainability behaviors of summer house vacationists. These questions were generated from the literature results. Questions for measuring the sustainability perception in the second part were prepared from the data obtained from the literature and the questionnaire of Turgut's full thesis (2013). After the analysis of the 14 questions in this section, five questions were excluded from the study due to the nonreliability and the invalidity. The last section, which is intended to collect the personal information of participants, consists of seven questions. Surveys were not implemented to foreign tourists due to the financial limitations and lack of time.

\subsection{Data analysis}

SPSS (Statistical Package for Social Sciences) 22.0 for Windows is used to analyze the data collected for this study program. Data has been described by calculating the mean and standard deviation, values frequency and percentage distribution tables. In the study, using varimax rotation and principal components method, descriptive factor analysis was performed to determine the current perceptions and environmental sustainability behavior of summer house vacationists on the environmental sustainability status.

According to kurtosis and skewness values and histograms of the scale questions in the survey, data was found to be normally distributed. Changes in environmental sustainability behaviors of summer house vacationists depending on the personal characteristics were examined by applying independent sample T-test and one-way analysis of variance (ANOVA). After One-way ANOVA test, the post hoc test was applied to determine and compare group mean differences. Tukey test was used for the homogeneous groups and Tamhane's T2 test was used for the non-homogeneous groups.

\section{Results and discussion}

\subsection{Reliability and validity}

The Cronbach's alpha coefficient model, which is used for internal consistency, was considered in the study. The Cronbach's alpha coefficient was found 0.789 for Purchase dimension, 0.726 for Protection dimension, 0.649 for Transportation dimension and 0.628 for Consumption dimension. The Cronbach's alpha coefficient was found 0.800 for the whole scale. In this context, it can be said scale to be reliable in all dimensions. After the factor analysis, Pearson correlation analysis was applied to see relationships of dimensions with each other. Dimensions are in a positive relationship with each other and this relationship with each other has been found at low levels ( $\mathrm{P}<0.05 ; \mathrm{r}=0.012,0.018,0.223$ and 0.468$)$. 
Table 1. Factors explaining environmental sustainability behavior of summer house vacationists

\begin{tabular}{|c|c|c|c|c|}
\hline Questions and Factors & Purchase & Protection & Transportation & Consumption \\
\hline Q 1 & 0.838 & & & \\
\hline Q 2 & 0.807 & & & \\
\hline Q 3 & 0.767 & & & \\
\hline Q 4 & & 0.854 & & \\
\hline Q 5 & & 0.823 & & \\
\hline Q 6 & & 0.552 & & \\
\hline Q 7 & & & 0.879 & \\
\hline Q 8 & & & 0.739 & \\
\hline Q 9 & & & 0.602 & \\
\hline Q 10 & & & & 0.808 \\
\hline Q 11 & & & & 0.769 \\
\hline Q 12 & & & & 0.540 \\
\hline Eigenvalue & 2.255 & 2.074 & 1.813 & 1.692 \\
\hline Variance Explanation Rate (\%) & 18.788 & 17.282 & 15.112 & 14.097 \\
\hline Cumulative Variance & 18.788 & 36.070 & 51.182 & 65.279 \\
\hline Cronbach's Alpha (For each Factor) & 0.789 & 0.726 & 0.649 & 0.628 \\
\hline Cronbach's Alpha (Whole Scale) & & & & \\
\hline Mean for Factors & 4.117 & 3.487 & 2.945 & 2.969 \\
\hline Standard Deviation for Factors & 0.908 & 1.112 & 1.082 & 0.709 \\
\hline Cumulative Variance & & & & \\
\hline
\end{tabular}

Four dimensions (factors) of 12 statements in the questionnaire obtained from factor analysis and the eigenvalues of them (Eigenvalue), the variance of rate, cumulative variance rate, factor loadings of each item included in the questionnaire are shown in Table 1. Also, results in reliability analysis of the factors, arithmetic mean and standard deviation values calculated separately for each factor were located in Table 1. According to the factor analysis results, it is seen that variables were grouped under four factors explaining $65.279 \%$ of the total variance.

According to Table 1, the eigenvalue of Purchase dimension including the four statements is 4.719, variance explanations rate of it is 18.823, the arithmetic mean value is 4.030 and standard deviation of it is 0.899 . The eigenvalue of the Consumption dimension including the four statements is 1.575 , variance explanations rate of it is 15.049, the arithmetic mean value is 3.430 and standard deviation of it is 0.970 . The eigenvalue of the Protection dimension including the three statements is 1.336 , variance explanations rate of it is 14.970, the arithmetic mean value is 3.487 and standard deviation of it is 1.112 . The eigenvalue of the Transportation dimension including the three statements is 1.050 , variance explanations rate of it is 13.159, the arithmetic mean value is 2.945 and standard deviation of it is 1.081 .

\subsection{Findings on demographic information of participants}

In this section, data on the personal characteristics of the participants were examined by applying the frequency and percentage analysis.

As seen in Table 2, 64 of 140 people participating in the study are women, 76 of them are male as well. $45 \%$ of respondents are married, and $55 \%$ of them are single. It is seen that $62.9 \%$ of the participants of are at undergraduate, $18.6 \%$ of them are at graduate, $13.6 \%$ of them are at high school and 5\% of them are at the primary level in terms of educational level. When the age groups of respondents are examined, $35 \%$ of respondents are between 26-35 years old, 20.7\% of them are between $0-25$ years old, $19.3 \%$ of them are between $36-45$ years old, $13.6 \%$ of them are between $46-55$ years old, $7.1 \%$ of them are over 66 years old and $4.3 \%$ of them are in between $56-65$ years old.

It is seen that $20 \%$ of respondents have 1301-2000 $\mathrm{TL}, 17.9 \%$ of them have $0-1300 \mathrm{TL}, 17.9 \%$ of them have $5001 \mathrm{TL}$ and above, $16.4 \%$ of them have 2001 $3000 \mathrm{TL}, 15 \%$ of them $3001-4000 \mathrm{TL}$ and $12.9 \%$ of them have 4001-5000 TL monthly income. $46.4 \%$ of respondents are working in the private sector, $26.4 \%$ of them are working in the public sector, $16.4 \%$ of them do not work in any job, and $15 \%$ of respondents are retirees. 
4.3. Sustainable environmental behavior results of summer house vacationists depending on the demographic information

In this section, changes in the sustainability of the behavior of summer house vacationists depending on the personal characteristics were examined by applying Independent Sample T-test and one-way analysis of variance (ANOVA). Tukey test and Tamhane's T2 test, which are posthoc tests, were used to determine differences between groups. According to the results, there are differences in especially marital status, occupation, income level, education level, age and visit duration of summer house vacationists' sustainability behavior. Analysis results are shown in Table 3.

Table 2. Demographic information of participants

\begin{tabular}{|c|c|c|c|c|c|c|c|}
\hline & Groups & $\mathbf{F}$ & $\%$ & & Groups & $\mathbf{F}$ & $\%$ \\
\hline \multirow{2}{*}{ Gender } & Women & 64 & 45.7 & \multirow{6}{*}{ Income } & $0-1300 \mathrm{TL}$ & 25 & 17.9 \\
\hline & Men & 76 & 54.3 & & $1301-2000 \mathrm{TL}$ & 28 & 20.0 \\
\hline \multirow{2}{*}{ Marital Status } & Single & 63 & 45.0 & & 2001-3000 TL & 23 & 16.4 \\
\hline & Married & 77 & 55.0 & & $3001-4000 \mathrm{TL}$ & 21 & 15.0 \\
\hline \multirow{6}{*}{ Education Level } & Drimary Schos & 7 & 50 & & $4001-5000 \mathrm{TL}$ & 18 & 12.9 \\
\hline & Prmary scnoor & 1 & 5.0 & & $5001 \mathrm{TL}$ and more & 25 & 17.9 \\
\hline & High School & 19 & 13.6 & \multirow{4}{*}{ Profession } & Private Sector & 65 & 46.4 \\
\hline & Undergraduate & 88 & 62.9 & & Public & 37 & 26.4 \\
\hline & \multirow{2}{*}{ Graduate } & \multirow{2}{*}{26} & \multirow{2}{*}{18.6} & & Retiree & 15 & 10.7 \\
\hline & & & & & Unemployed & 23 & 16.4 \\
\hline \multirow{5}{*}{ Age } & $0-25$ & 29 & 20.7 & \multirow{5}{*}{ Visit time } & $1-5$ year & 45 & 32.1 \\
\hline & $26-35$ & 49 & 35.0 & & 6-10 year & 41 & 29.3 \\
\hline & $36-45$ & 27 & 19.3 & & $11-15$ year & 18 & 12.9 \\
\hline & $46-55$ & 19 & 13.6 & & $16-20$ year & 18 & 12.9 \\
\hline & $56-65$ & 6 & 4.3 & & 21 years and more & 18 & 12.9 \\
\hline
\end{tabular}

Table 3. Sustainable environmental behaviors of summer house vacationists depending on the demographic information by t-test and ANOVA

\begin{tabular}{|l|l|c|c|c|c|c|c|}
\hline \multirow{2}{*}{ Factors } & \multicolumn{2}{|l|}{ t-test } & \multicolumn{2}{l|}{ One Way Variance Annalise (ANOVA) } \\
\cline { 2 - 9 } & Gender & $\begin{array}{c}\text { Marital } \\
\text { Status }\end{array}$ & Profession & Income & $\begin{array}{c}\text { Education } \\
\text { Level }\end{array}$ & Age & Visit Time \\
\hline Consumption & 0.056 & 0.760 & $\mathbf{0 . 0 0 0 *}$ & $\mathbf{0 . 0 3 2}^{*}$ & $\mathbf{0 . 0 2 1} *$ & 0.061 & $\mathbf{0 . 0 0 7}$ \\
\hline Transportation & 0.372 & 0.060 & 0.871 & $\mathbf{0 . 0 0 3}^{*}$ & 0.539 & $\mathbf{0 . 0 0 2 *}$ & 0.109 \\
\hline Protect & 0.441 & 0.063 & 0.118 & 0.290 & 0.280 & 0.155 & $\mathbf{0 . 0 4 2}$ \\
\hline Purchase & 0.406 & $\mathbf{0 . 0 3 9}$ & 0.415 & 0.063 & 0.229 & 0.063 & $\mathbf{0 . 0 4} *$ \\
\hline
\end{tabular}

According to the participants' marital status, their sustainability behavior level shows a statistically significant difference $\left(\mathrm{t}_{0,05} ; 138=-2.085\right)$ in Purchase dimension. Accordingly, married participants' environmentally sustainable behavior level $(\overline{\mathrm{x}}=$ 4.2597) is higher than the single of participants' $(\overline{\mathrm{x}}=$ 3.9418) in Purchasing dimension.

In terms of the participants' professions, their sustainability behavior level shows a statistically significant difference $(\mathrm{F}(3,136)=6.417, \mathrm{p}<0.05, \mathrm{D}=$ 0.124) in Consumption dimension. It has been found by The Tukey's multiple comparison tests that the differences are between retirees $(\overline{\mathrm{x}}=3.4444)$ and private sector employees $(\mathrm{x}=2.7436)$ and between private sector employees $(\overline{\mathrm{x}}=2.7436)$ and public sector employees $(\mathrm{x}=3.1982)$. Based on these results; retirees and public sector participants show less environmentally sustainable behavior than the private sector employees in Consumption dimension. Hence the private sector employees among participants were observed to show a more sensitive attitude towards the environment compared to other groups.

Considering the participants' income level, their sustainability behavior level shows a statistically significant difference in Consumption dimension ( $\mathrm{F}(5$, $134)=2.528, \mathrm{p}<0.05, \mathrm{D}=0.086)$ and Transportation 
dimension $(\mathrm{F}(5,134)=3.728, \mathrm{p}<0.05 \mathrm{D}=0,122)$. It has been found by The Tukey's and Tamhane's T2 multiple comparison tests that the environmentally sustainable behavior level of participants with the monthly income of $1301-2000$ TL $(\bar{x}=3.2857)$ is lower than participants' with the monthly income of 01301 TL $(\overline{\mathrm{x}}=2.4815)$ in Consumption dimension. These different values may seem important between the groups, but there is indeed no statistically significant difference between them. On the other hand, it is found that the environmentally sustainable behavior level of participants with the monthly income 5001 TL and over $(\bar{x}=3.6267)$ is higher than participants' with the monthly income of 2001-3000 TL $(\overline{\mathrm{x}}=2.5942)$ in Transportation dimension.

According to the participants' education level, their sustainability behavior level shows a statistically significant difference $(\mathrm{F}(3,136)=3,360, \mathrm{p}<0.05, \mathrm{D}$ $=0,069$ ) in Consumption dimension. It has been found by The Tukey's multiple comparison tests that the differences are between participants with the postgraduate degree $(\overline{\mathrm{x}}=3.2692)$ and participants with the undergraduate degree $(x=2.8409)$. Based on these results; participants with undergraduate degree show more environmentally sustainable behavior than participants with the postgraduate degree in Consumption dimension.

There is a statistically significant difference on sustainability behavior level in Transportation dimension according to the participants' ages (F (5, $134)=4.121, p<0.05, D=0,133)$. It has been found by Tamhane's T2 multiple comparison tests in Transportation dimension that environmentally sustainable behavior level of participants between 4655-year age group $(\overline{\mathrm{x}}=3.772)$ are higher than participants' with $36-45$-year age group $(\overline{\mathrm{x}}=2.6173)$. There is no statistically significant difference in value between these groups, the fact that they seem to be different.

Additionally, the sustainability behavior level shows a statistically significant difference in Protection dimension according to the visit duration of the participants, $(\mathrm{F}(4,135)=2.551, \mathrm{p}<0.05, \mathrm{D}=$ $0,070)$ Consumption $(\mathrm{F}(4,135)=3.686, \mathrm{p}<0.05 \mathrm{D}=$ $0,098)$ and Purchase $(F(4,135)=2.570, p<0.05, \mathrm{~b}=$ 0.071 ) dimensions. After Tukey's multiple comparison tests, there is no statistically significant difference in value between these groups, the fact that they seem to be different in Protection dimension. It has been found by Tukey's multiple comparison test in Consumption dimension that environmentally sustainable behavior level of participants with visit times over 20 years $(\overline{\mathrm{x}}=$ 3.4074 are higher than participants between 1-5 years $(\bar{x}=2.7111)$. After Tamhane's T2 multiple comparison test, there is no statistically significant difference in value between these groups, the fact that they seem to be different in Purchase dimension.

\subsection{Results of participants' thoughts on the environmental sustainability}

In this section, the findings related to the participants' thoughts on a sustainable environment were examined by applying mean, standard deviation, frequency and percentage descriptive statistics.

Table 3. Are you a member of any association for environmental issues?

\begin{tabular}{|c|c|c|}
\hline & F & \% \\
\hline No & 125 & 89.3 \\
\hline Yes & 15 & 10.7 \\
\hline Total & 140 & 100 \\
\hline
\end{tabular}

As seen in Table 3, while $89.3 \%$ of the participants does not register any association for environmental issues, $10.7 \%$ of them are members of an environmental association/foundation/organization.

Table 4. People's intervention to nature would lead to catastrophic.

\begin{tabular}{|l|c|c|}
\hline & F & \% \\
\hline Strongly disagree & 17 & 12.1 \\
\hline Disagree & 11 & 7.9 \\
\hline Neither agree nor disagree & 21 & 15.0 \\
\hline Agree & 27 & 19.3 \\
\hline Strongly Agree & 64 & 45.7 \\
\hline
\end{tabular}

As seen in Table 4, the majority of respondents (strongly agree and agree 65\%) carry the thought that people's intervention to nature would lead to catastrophic.

Table 5. The earth is an island with limited resources.

\begin{tabular}{|l|c|c|}
\hline & F & $\%$ \\
\hline Strongly disagree & 65 & 46.4 \\
\hline Disagree & 31 & 22.1 \\
\hline Neither agree nor disagree & 16 & 11.4 \\
\hline Agree & 11 & 7.9 \\
\hline Strongly Agree & 17 & 12.1 \\
\hline
\end{tabular}


As seen in Table 5, the majority of participants (strongly disagree and disagree $68.5 \%$ ) does not carry the idea that the earth is an island with limited resources.

Table 6. I care about the price in case of ecofriendly products.

\begin{tabular}{|l|c|c|}
\hline & F & $\mathbf{\%}$ \\
\hline Strongly disagree & 13 & 9.3 \\
\hline Disagree & 15 & 10.7 \\
\hline Neither agree nor disagree & 37 & 26.4 \\
\hline Agree & 30 & 21.4 \\
\hline Strongly Agree & 45 & 32.1 \\
\hline
\end{tabular}

The majority of the participants (strongly agree and agree $68.5 \%$ ), as shown in Table 6 , reported that they care about the price in case of eco-friendly products. In this context, the participants concluded that they tend to pay more for environmentally friendly products.

\section{Conclusion and suggestions}

The overall objective of sustainable tourism is to leave a livable space for the future generations by ensuring the sustainability of culture, ecology and biodiversity and societies. Thus, this study conducted a review on the sustainability that opposes to rapid and unplanned settlements, throughout history. Within the scope of the research, the behaviors of the summer house vacationists during their holiday are examined in terms of environmental sustainability

As a result of the research, it is apparent that the summer house vacationists exhibit sustainable behaviors in different dimensions. Purchase, transportation and consumption of the nature behaviors are within the dimensions that are considered depending on the environment. These dimensions have shown differences in the demographic context in general. It has been seen that married people present more sensitive behaviors to environmental and ecologic products in the purchasing dimension than single people. However, the tendency to buy products that are more expensive is falling. This shows that the environmental products are generally preferable in the case of the price. It is seen that if the price is close to normal, the summer house vacationists will prefer the ecologic and sensitive products.

Income is also important in the context of transportation as well as purchasing. Context is also important. As a result of the research, it is ascertained that the summer house vacationists with higher income present more sensitive behavior than the ones with lower income. It is a remarkable result that in terms of transportation, public transportation and bikes are preferable for the summer house vacationists with higher income. In the previous studies, it was expressed that the ones with higher income tend to be fonder of luxury and were away from environmental behaviors whereas in this study it is seen that they are found to be more attentive to the environment. This situation is an indicator that egocentrism is put on the back burner from the point of the ones with high income and vital standards can show variability with the sense of the holiday. In the dimension of consumption of the natural resources, the behaviors that consumers present in the areas that are specific to themselves. The size of the consumption of natural resources has been demonstrated for the behavior of their specific areas of the consumer. Private sector employees were found to be relatively more sensitive than the public servant and retired people in terms of the consumption of energy, water and so on. While they are trying to take precautions in the consumption of electricity and water, and washing the bed linen and towels daily in hotels today, it is an important step that in the houses, the summer house vacationists show these behaviors by themselves. On the other hand, when it is assessed in terms of the summer house vacationists that have been visiting the same area for a long time, it has been seen that while this group is expected to be more sensitive to the area, the summer house vacationists that have spent a short time like 5 years are more sensitive to the area. It is thought that this situation may be caused by habits of long-term visitors and desensitization to the area. However, to reveal the main reasons, there is a need for a study to bring into open the connection between visitation periods and environmental sustainability behavior.

When the findings related to the summer house vacationists' sustainability of the environment are evaluated the dominant idea, sustainability is undervalued and the situation is by and large negative. Despite the view that the consequences of human intervention are disastrous for nature, the summer house vacationists don't see the world as an island with scarce resources. According to that, although nature is harmed due to human intervention, it will eventually be renewed in time and resources will not be depleted. 
Opinions and behaviors related to the environmental sustainability of the summer house vacationists were measured in this study. This research is limited by the number of data collected due to material and time constraints. Therefore, the implementation of the research to a larger sample group will provide more results in terms of generalizability.

\section{References}

Beyhan, Ş. G. and Ünügür, S. M. (2010). Çağdaş gereksinmeler bağlamında sürdürülebilir turizm ve kimlik modeli. İtüdergisi/a, 4(2).

Bodur, M., and Sarigöllü, E. (2005). Environmental Sensitivity in a Developing Country Consumer Classification and Implications. Environment and Behavior, 37(4), 487-510.

Budeanu, A. (2007). Sustainable tourist behavior - a discusion of opportunities for change, International Journal of Consumer Studies, 31, 499-508.

Choi, S. and Ng, A. (2011). Environmental and economic dimensions of sustainability and price effects on consumer responses. Journal of business ethics, 104(2), 269-282.

Elliott, R. (2013). The taste for green: the possibilities and dynamics of status differentiation through "green" consumption. Poetics, 41(3), 294-322.

Finisterra do Paco, A. M. and Raposo, M. L. B. (2010). Green consumer market segmentation: empirical findings from Portugal. International Journal of Consumer Studies, 34(4), 429-436.

Gilg, A., Barr, S. and Ford, N. (2005). Green consumption or sustainable lifestyles? Identifying the sustainable consumer. Futures, 37(6), 481-504.

Grove, S. J., Fisk, R. P., Pickett, G. M. and Kangun, N. (1996). Going green in the service sector: Social responsibility issues, implications and implementation. European journal of marketing, 30(5), 56-66.

Han, H., Hsu, L. T. J. and Sheu, C. (2010). Application of the theory of planned behavior to green hotel choice: Testing the effect of environmental friendly activities. Tourism Management, 31(3), 325-334.

Jansson, J., Marell, A. and Nordlund, A. (2010). Green consumer behavior: determinants of curtailment and ecoinnovation adoption. Journal of consumer marketing, 27(4), 358-370

Jones, P., Clarke-Hill, C., Comfort, D. and Hillier, D. (2008). Marketing and sustainability. Marketing Intelligence \& Planning, 26(2), 123-130.
Karaca, S. (2013). Tüketicilerin Yesil Ürünlere Iliskin Tutumlarinin Incelenmesine Yönelik Bir Arastirma. Ege Akademik Bakiş, 13(1), 99.

Khare, A. (2014). Consumers' susceptibility to interpersonal influence as a determining factor of ecologically conscious behavior. Marketing Intelligence \& Planning, 32(1), 2-20.

Leung, Y. F., Marion, J. L. and Farrell, T. A. (2008). Recreation ecology in sustainable tourism and ecotourism: a strengthening role. Tourism, recreation, and sustainability: Linking culture and the environment, 19-36.

Lin, P. C. and Huang, Y. H. (2012). The influence factors on choice behavior regarding green products based on the theory of consumption values. Journal of Cleaner Production, 22(1), 11-18.

Mansfeld, J. (1995). The 'value stretch' model and its implication in detecting tourists' class-differentiated destination choice. Journal of Travel and Tourism Marketing 4 (3), 71-92. from Miller, A. (2010) Consumerism in Sustainable Tourism: A Survey of UK Consumers Graham, Journal of Sustainable Tourism. 11 (1). 17-39.

Millar, M. and Baloglu, S. (2011). Hotel guests' preferences for green guest room attributes. Cornell Hospitality Quarterly, 52(3), 302-311.

Swarbrooke, J (1996) Understanding the tourist - some thoughts on consumer behaviour research in tourism. Insights (November), A67-A76. from Miller, A. (2010) Consumerism in Sustainable Tourism: A Survey of UK Consumers Graham, Journal of Sustainable Tourism. 11 (1). 17-39.

Peattie, K. (2001). Golden goose or wild goose? The hunt for the green consumer. Business strategy and the environment, 10(4), 187-199.

Turgut, U. (2013). Kıyı Otellerinde Çevresel Yönetimi Uygulamaları, Yayınlanmamış Yüksek Lisans Tezi, Muğla: Sttk1 Koçman Üniversitesi.

Yaraş, E., Akın, E. and Şakacı, B. K. (2011). Tüketicilerin çevre bilinci düzeylerini belirlemeye yönelik bir araştırma. 9(35), 117-126.

Yi, S., Li, X. and Jai, T. M. C. (2016). Hotel guests' perception of best green practices: A content analysis of online reviews. Tourism and Hospitality Research, 1-12

Yücel, F. (2003). Sürdürülebilir kalkınmanın sağlanmasında çevre korumanın ve ekonomik kalkınmanın karşıtlığı ve birlikteliği. Çukurova Üniversitesi Sosyal Bilimler Enstitüsü Dergisi, 11(11), 100-120.

http://epi.yale.edu/reports/2016-report, Environmental Performance Index-EPI (Erişim tarihi:17.06.2016). 